\title{
TREATMENT PLANNING SYSTEM (TPS) KANKER PAYUDARA MENGGUNAKAN TEKNIK 3DCRT
}

\author{
Wida Farhiyati1), Rinarto Subroto2), I Wayan Ari Makmur²), Nurul Qomariyah'1), Rahadi Wirawan') \\ 1)Program Studi Fisika, FMIPA, Universitas Mataram, Mataram, Indonesia \\ ${ }^{2}$ Instalasi Radioterapi, Rumah Sakit Umum Daerah Provinsi NTB, Mataram, Indonesia
}

Corresponding author : Rahadi Wirawan

E-mail : rwirawan@unram.ac.id

\section{Diterima 20 April 2020, Disetujui 28 April 2020}

\begin{abstract}
ABSTRAK
Penelitian ini bertujuan untuk mengevaluasi hasil simulasi TPS teknik 3DCRT pada kasus kanker payudara agar sesuai dengan standar yang diizinkan International Commission on Radiation Units and Measurements (ICRU). Proses TPS menggunakan program Eclipse dengan algoritma Anisotropic Analytical Algorithm. Kurva histogram dosis volume kumulatif 3DCRT dianalisis untuk mendapatkan dosis radiasi yang diterima organ at risk (OAR) paru-paru kiri, paru-paru kanan dan jantung. Hasil TPS menunjukkan dosis yang diterima OAR berada di bawah batas ambang yang ditentukan yaitu paru-paru kiri dengan mean dose 54,7 cGy yang melingkupi volume $1238,5 \mathrm{~cm}^{3}$ dan pada paru-paru kanan dosis mean dose 2113,2 cGy melingkupi volume $1474,5 \mathrm{~cm}^{3}$ serta pada jantung mean dose 96,5 cGy melingkupi volume $175,5 \mathrm{~cm}^{3}$. Simulasi TPS yang dilakukan berhasil mendapatkan data perencanaan penyinaran kasus kanker payudara yang memenuhi syarat dosis relatif yang melingkupi volume PTV yang diizinkan ICRU (volume terlingkupi 95\%-107\%) yaitu besarnya dosis relatif untuk target sebesar $95 \%$ yang melingkupi $95,5 \%$ volume target.
\end{abstract}

Kata kunci: radioterapi, TPS, dosis, PTV, OAR.

\begin{abstract}
This study objective is to evaluate the simulation results of the 3DCRT technique TPS in breast cancer cases to conform to the standards permitted by the International Commission on Radiation Units and Measurements (ICRU). The TPS process uses the Eclipse program with the Anisotropic Analytical Algorithm algorithm. The 3DCRT cumulative dose-volume histogram curve was analyzed to obtain the absorbed dose received by the organ at risk (OAR) of the left lung, right lung and heart. The TPS results show that the dose received by OAR was below the prescribed threshold of the left lung with a mean dose of $54.7 \mathrm{cGy}$ covering a volume of $1238.5 \mathrm{~cm} 3$ and to the right lung the mean dose of 2113.2 cGy surrounding the volume of $1474,5 \mathrm{~cm} 3$ and at the heart the mean dose of $96.5 \mathrm{cGy}$ covers a volume of $175.5 \mathrm{~cm} 3$. TPS simulation carried out successfully obtained data on the planning of radiation from breast cancer cases that met the relative dosage requirements that covered the volume of PTV permitted by ICRU (95\% -107\% enclosed volume), that is, the relative dose for the target of $95 \%$ which covered $95.5 \%$ of the target volume.
\end{abstract}

Keywords: radiotherapy, TPS, dose, PTV, OAR.

\section{PENDAHULUAN}

Kanker merupakan perubahan sel menjadi tidak normal dan mengalami peningkatan jumlah yang tidak terkendali. Salah satu kasus kanker yang banyak dialami dan dijumpai pada wanita adalah kanker payudara. Mamografi dan Magnetic Resonance Imaging (MRI) digunakan untuk skrining pendeteksian kangker payudara (Sun, et al., 2017). Adapun metode yang dapat diaplikasikan untuk memusnahkan sel-sel kanker tersebut adalah dengan menembakkan radiasi pengion dosis tinggi atau radioterapi berkas eksternal. Radiasi yang ditembakkan tersebut dapat merusak sel-sel kanker sehingga menghambat proses multiplikasi selsel kanker tersebut. Sementara itu, penggunaan radiasi pengion dosis tinggi dapat juga memberikan efek merusak jaringan normal (Organ at Risk-OAR). OAR untuk kasus kanker payudara adalah paru-paru dan jantung. Oleh karenanya diperlukan suatu perencanaan radioterapi yang cermat dan akurat.

Perencanaan tersebut dapat dilakukan secara terkomputerisasi atau computerized treatment planning system (TPS). TPS 
bertujuan memaksimalkan dosis yang diterima target (sel kanker) dan meminimalkan dosis pada jaringan normal (Evans, 2005). Salah satu teknik yang dapat diaplikasikan adalah 3DCRT (Three-Dimensional Conformal Radiation Therapy). Rekonstruksi citra 3D memungkinkan untuk mengetahui posisi dan volume organ sehingga penentuan dosis radioterapi menjadi lebih akurat dan dapat membantu menentukan dosis yang akan diterima oleh organ at risk (Siti dkk., 2013). Seperti halnya penelitian Sugyanti dkk. (2015) yang menganalisis dosis radiasi yang diterima paru-paru untuk citra kanker payudara. Sementara Gerardina et al. (2016) berhasil mengembangkan perencanaan 3DCRT yang mudah dan sederhana untuk pasien dengan payudara berukuran besar/terjumbai dan/atau pasien dengan indeks massa tubuh (BMI) tinggi.

Perencanaan perlakuan radiasi dengan teknik $3 D$ terdiri atas informasi dosis dari matriks 3D anatomi tubuh pasien, dimana penentuan volume merupakan persyaratan utama untuk mendapatkan dosis yang akurat. Volume yang dimaksud antara lain planning target volume (PTV), Organ at Risk (OAR) (Neal, 2007; Berthelsen et al., 2007). Informasi distribusi dosis untuk 3D ditampilkan dalam bentuk histogram dosis volume (Dose Volume Histogram-DVH) dan digunakan untuk evaluasi kuantitatif rencana perlakuan. $D V H$ merangkum informasi yang terkandung dalam distribusi dosis 3D dan merupakan alat yang sangat kuat untuk evaluasi kuantitatif rencana perawatan (Parker \& Patrocinio, 2005). Pada tulisan ini, diuraikan hasil analisis simulasi TPS teknik 3DCRT pada suatu kasus kanker payudara. Analisis ditujukan untuk mendapatkan persentase dosis yang diterima target (PTV) dan OAR di sekitar target tersebut agar sesuai dengan standar yang diizinkan International Commission on Radiation Units and Measurements (ICRU).

\section{METODE PENELITIAN}

Peralatan yang digunakan antara lain seperangkat hardware (CPU, High resolution graphics monitor, hard disc, disks/CD-ROM, keyboard dan mouse, digitizer, laser, backup storage facility, network connections) dan software Eclipse untuk proses TPS (meliputi Input Routines, bentuk anatomi, beam geometry (virtual simulation), kalkulasi dosis, histogram dosis volume $(D V H)$, Digital Reconstruction Radiographic (DRR). Simulasi dilakukan pada Instalasi Radioterapi, Rumah Sakit Umum Daerah Provinsi NTB.

Untuk TPS menggunakan program Eclipse dengan algoritma Anisotropic
Analytical Algorithm (AAA), dimana untuk mempermudah penentuan dosis hanya dengan satu titik dengan akurasi $94 \%$. Adapun diagram alir proses TPS dapat diamati pada Gambar 1.

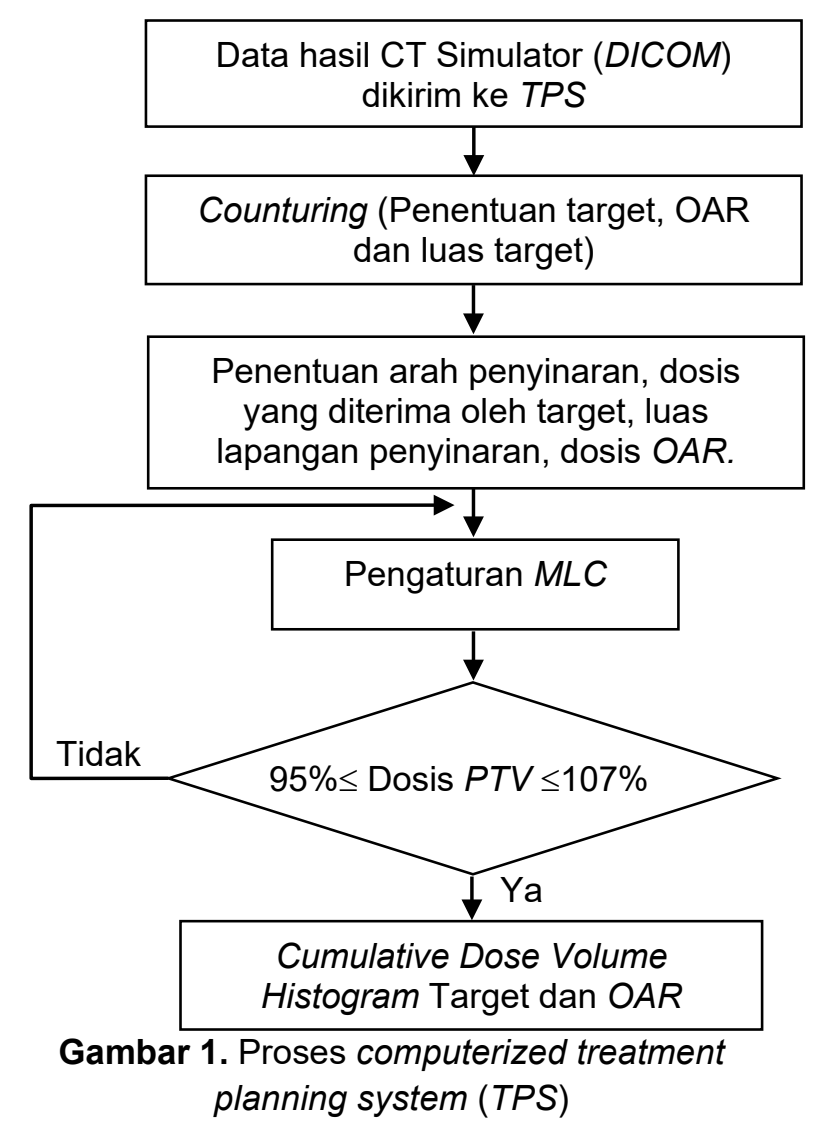

Luaran proses TPS adalah grafik hubungan antara persentase dosis yang diterima target terhadap persentase volume target pada histogram dosis volume kumulatif $(C D V H)$. Ketika persentase dosis relative yang diterima oleh target sama dengan persentase volume target maka hasil perencanaan sudah sesuai dengan ketentuan yang ditetapkan. ICRU No. 50 merekomendasikan bahwa persentase dosis yang berada pada PTV berkisar antara $95 \%$ sampai $107 \%$, dimana dosis $100 \%$ berada pada pusat PTV (Landberg et al., 1999; Parker \& Patrocinio, 2005). Namun jika persentase dosis yang diterima lebih kecil atau lebih besar dari persentase volume maka dilakukan pengaturan filter baji (wedge) pembentuk profil berkas isodose atau multileaf collimator (MLC) agar dosis maksimum diterima target, sementara dosis minimum diterima OAR. Pada proses TPS untuk distribusi dosis penyinaran target volume ini digunakan sumber energi radiasi $6 \mathrm{MV}$.

\section{HASIL DAN PEMBAHASAN}

Simulasi dan perhitungan dosis radiasi (dosis serap) dilakukan oleh medical physicist/ dosimetris menggunakan TPS yang 
merupakan kinerja perhitungan algoritma, Anisotropic Analytical Algorithm, dimana hanya diperlukan 1 titik dengan akurasi 94\%. Teknik yang digunakan untuk membuat perencanaan penyinaran pada kasus kanker payudara adalah teknik 3DCRT. Teknik ini memerlukan MLC untuk memblok radiasi dan membentuk lapangan yang tidak beraturan. Berdasarkan teori untuk kanker payudara dengan teknik 3D dibutuhkan 4 lapangan penyinaran yaitu 2 arah untuk tangensial yang menyerempet target dengan tujuan untuk mengurangi dosis di paruparu, arah $0^{\circ}$ untuk modul di daerah supraklavikula dan arah $180^{\circ}$ untuk kelenjar diaksila atau di daerah ketiak. Adanya variasi bentuk payudara yang berbeda-beda dan bentuk kanker yang berbeda, maka arah penyinaran untuk kasus kanker payudara menggunakan berkas tangensial. Penggunaan berkas tangensial bertujuan untuk meminimalkan radiasi yang diterima oleh organ at risk $(O A R)$ seperti paru-paru, laring dan jantung.

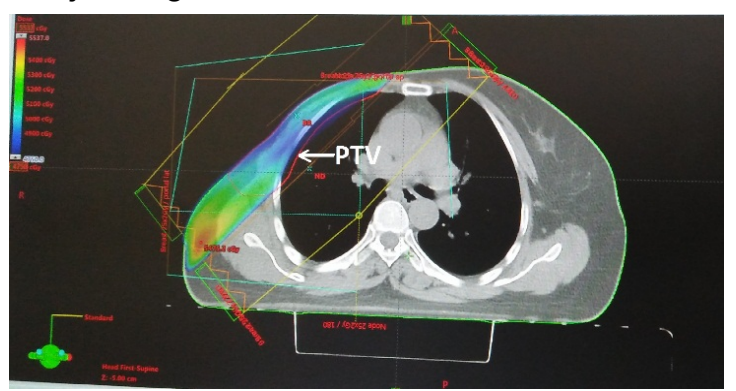

(a) Arah Aksial

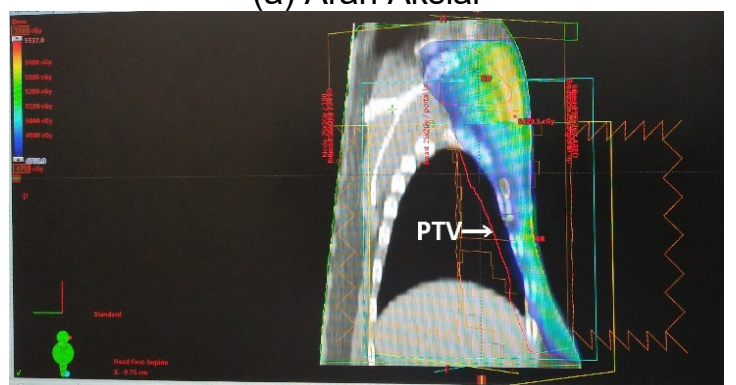

(b) Arah Sagital

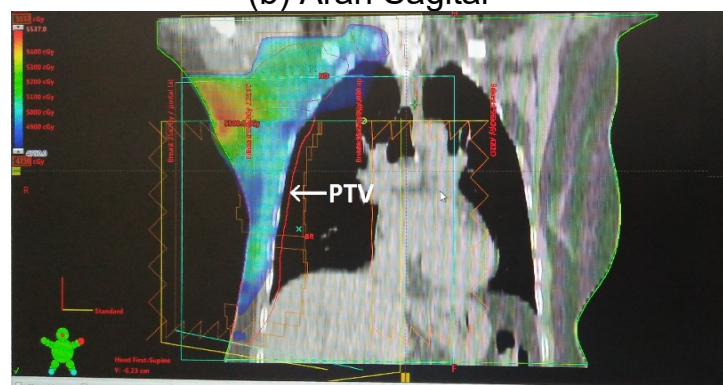

(c) Arah Transversal

Gambar 2. Visualisasi simulasi penyinaran
Pemodelan penyinaran dilakukan pada tiga sisi yaitu sisi aksial (atas), sisi sagital (samping) dan sisi transversal (depan) seperti ditampilkan pada Gambar 2. Adapun posisi tumor (kanker) berada di payudara kanan (Mammae Dextra). Pada gambar terlihat tanda panah yang menunjukkan posisi target (PTV), sedangkan gradasi warna yang ada pada target mengindikasikan tingkat paparan radiasi. Warna merah mempunyai dosis yang lebih tinggi dibandingkan warna hijau, begitu juga warna hijau memiliki dosis radiasi lebih tinggi daripada warna biru. Distribusi dosis ini dipengaruhi oleh luas lapangan, arah/sudut penyinaran, besar energi yang digunakan dan dipengaruhi oleh aksesoris seperti wedge. Untuk menghomogenkan dan menurunkan hospot maka digunakan teknik Field in Field $(F I F)$. Sementara itu, pengaturan berkas radiasi menggunakan Beam's Eye View display (BEV) untuk memilih luas lapangan penyinaran, arah sinar, bentuk dan ukuran sinar yang sesuai dengan bentuk dan ukuran tumor.

Prediksi dosis radiasi yang diterima oleh masing-masing organ at risk (OAR) seperti paru-paru kiri, paru-paru kanan dan jantung dapat diamati dari kurva histogram volume dosis kumulatif (Gambar 3) yang dihasilkan. Parameter dosis yang ditampilkan pada hasil analisis $C D V H$ (keterangan Gambar 3) meliputi dosis minimum dan maksimum pada target (min dose dan max dose), dosis rata-rata pada target (mean dose), dosis pada target dengan frekuensi terbesar (modal dose), dan dosis pada persentase volume target 50\% (median dose).

Hasil TPS yang dipaparkan melalui kurva histogram volume dosis kumulatif (Gambar 3) menunjukkan dosis minimum yang diterima paru-paru kiri sebesar 1,8 cGy dengan mean dose 54,7 cGy dan melingkupi volume $1238,5 \mathrm{~cm}^{3}$. Dosis ini masih berada di bawah batas dosis paru-paru dimana mean lung dose $\leq 20$ Gy (Kong et al., 2011). Sementara untuk paru-paru kanan, dosis minimum yang diterima sebesar 48,3 cGy (mean dose 2113,2 cGy) yang melingkupi volume $1474,5 \mathrm{~cm}^{3}$. Dosis yang diterima paru-paru kanan lebih besar dikarenakan keberadaan tumor target penyinaran di payudara kanan. 


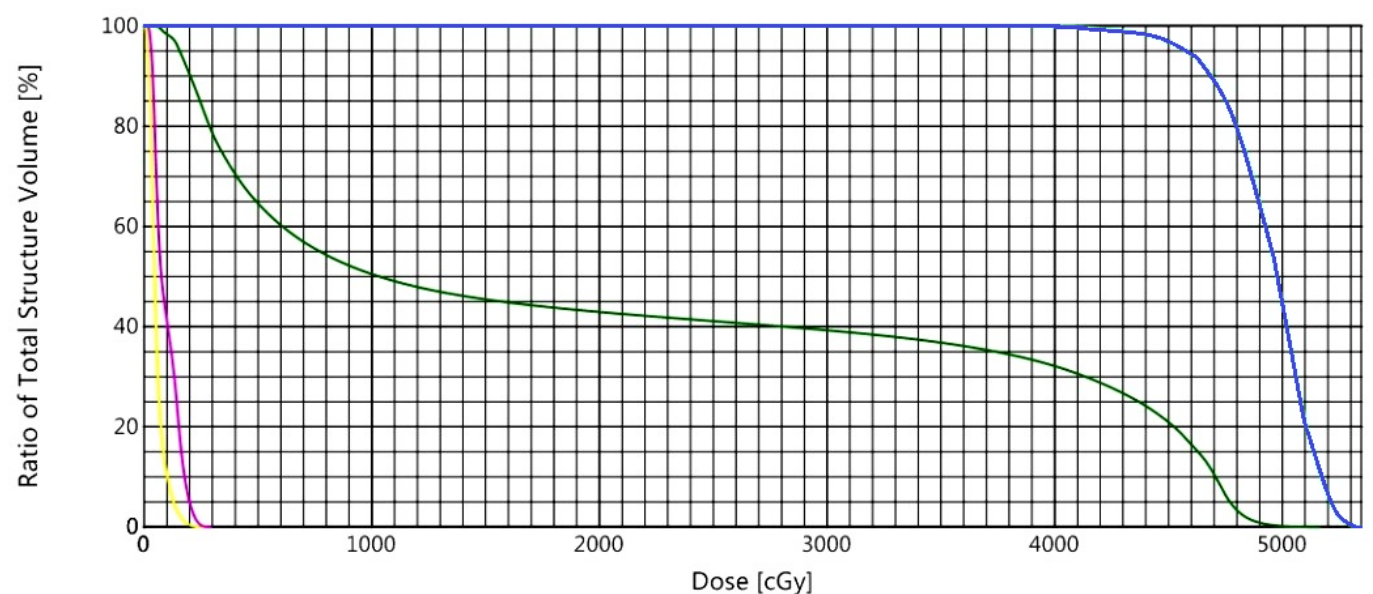

\begin{tabular}{|c|c|c|c|c|c|c|c|c|c|c|}
\hline DVH & Structure & re sta & verage $[\mathrm{s} / \mathrm{N}]$ & Volume & $\operatorname{Min}$ & Max & Mer & Mo & Median Dose & Std Dev \\
\hline- & 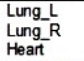 & $\begin{array}{l}\text { Apporoved } \\
\text { Appoveded } \\
\text { Appovoved }\end{array}$ & $\begin{array}{l}10.0 / 100.0 \\
10.0 / 100.0 \\
100.0 / 100.0\end{array}$ & 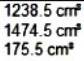 & $\begin{array}{l}1.8 \mathrm{cGy} \\
483.3 \mathrm{cg} \\
13.5 \mathrm{cog}\end{array}$ & $\begin{array}{l}279.2 \mathrm{cGy} \\
5169.7 \mathrm{cG} \\
297.3 \mathrm{cGy}\end{array}$ & $\begin{array}{l}54.7 \mathrm{Gg} \\
21132 \mathrm{cG} \\
96.5 \mathrm{cGy}\end{array}$ & $\begin{array}{l}35.2 \mathrm{ccy} \\
266.8 \mathrm{cGy} \\
50.2 \mathrm{coy}\end{array}$ & 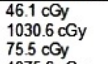 & $\begin{array}{l}34.9 \mathrm{cGy} \\
1906.3 \mathrm{COy} \\
56.0 \mathrm{cGy}\end{array}$ \\
\hline & & & $100.0 / 1000$. & & & & & & & \\
\hline
\end{tabular}

Gambar 3. Cumulative Dose Volume Histogram (CDVH)

Untuk jantung, dosis minimum yang diterima sebesar 13,5 cGy (mean dose 96,5 cGy) melingkupi volume $175,5 \mathrm{~cm}^{3}$ dengan $<10 \%$ dosis melingkupi batas ambang 25 cGy. Dosis yang diterima organ jantung masih berada di bawah batas ambang untuk jantung yaitu $\leq 40$ Gy (Kong et al., 2011). Hasil TPS telah berhasil merencanakan penyinaran radiasi untuk kanker payudara dengan prediksi dosis yang diterima OAR berada di bawah batas ambang yang ditentukan sehingga tidak merusak jaringan sehat.

\section{SIMPULAN DAN SARAN}

Simulasi TPS yang dilakukan berhasil mendapatkan data perencanaan penyinaran untuk kasus kanker payudara yang memenuhi syarat dosis relatif yang melingkupi volume PTV yang diizinkan ICRU (volume terlingkupi 95\%-107\%) yaitu besarnya dosis relatif untuk target sebesar 95\% yang melingkupi 95,5\% volume target. Sementara untuk OAR di sekitar payudara seperti paru-paru dan jantung menerima dosis di bawah batas ambang.

\section{UCAPAN TERIMA KASIH}

Ucapan terima kasih kami sampaikan kepada Instalasi Radioterapi, Rumah Sakit Umum Daerah Provinsi NTB atas ijin menggunakan perangkat simulasi TPS.

\section{DAFTAR RUJUKAN}

Berthelsen et al., (2007). What_s new in target volume definition for radiologists in ICRU Report 71? How can the ICRU volume definitions be integrated in clinical practice?, Cancer Imaging 7, 104-116.

Evans, M.D.C. (2005). "Computerized Treatment Planning Systems For External Photon Beam Radiotherapy", Radiation oncology physics: A handbook for teachers and students - E.B. Podgorsak, IAEA, Austria.

Gerardina, S., et al. (2016). A new threedimensional conformal radiotherapy (3DCRT) technique for large breast and/or high body mass index patients: evaluation of a novel fields assessment aimed to reduce extratarget-tissue irradiation, British Journal of Radiology; 89: 20160039,1-9.

Kong, FM., et al. (2011). Consideration Of Dose Limits For Organs At Risk Ofthoracic Radiotherapy: Atlas For Lung, Proximalbronchial Tree, Esophagus, Spinal Cord, Ribs, Andbrachial Plexus, Int J Radiat Oncol Biol Phys. 2011 December 1; 81(5): 1442-1457. 
Landberg, T. et al. (1999). "Prescribing, Recording and Reporting Photon Beam Therapy (Supplement to ICRU Report 50)", ICRU Report 50.

Neal, A. (2007). "Target Definition", Handbook of radiotherapy physiscs: theory and practice/edited by P. Mayles, A. Nahum, and J.C. Rosenwald, Taylor \& Francis CRC Press.

Parker, W. \& Patrocinio, H. (2005). "Clinical Treatment Planning In External Photon Beam Radiotherapy", Radiation oncology physics: a handbook for teachers and students - E.B. Podgorsak, IAEA, Austria.

Siti, A'isyah., Kusworo, Adi., Choirul, Anam. (2013). Pembuatan Program Rekonstruksi Kontur Citra 3D Pada Organ Menggunakan Matlab 2008a, Youngster Physics Journal. Universitas Diponegoro, Semarang. 1(5), 209-216.

Sugianty Syam, Syamsir Dewang, Bualkar Abdullah. (2015). Analisis Dosis Radiasi Pada Paru-paru Untuk Pasien Kanker Payudara Dengan Treatment Sinar-X 6 MV, http://repository.unhas.ac.id/handle/ $123456789 / 14553$.

Sun, et al. (2017). Review Risk Factors and Preventions of Breast Cancer, International Journal of Biological Sciences 2017; 13(11): 1387-1397. 